\title{
Paper
}

\section{Effects of an Audience Response System for Peer Evaluations of Student Presentations in an Engineering Ethics Course}

\author{
Michiaki SHISHIDO*† \\ MitsuaKi YAMADA ${ }^{\dagger}$ \\ Member, \\ Kodai SAITO ${ }^{\dagger}$ \\ Non-member \\ RYOJI ONODERA ${ }^{\dagger}$ \\ Non-member, \\ Tsukasa Sato ${ }^{\dagger}$ \\ Non-member
}

(Received December 26, 2017, revised September 20, 2018)

\begin{abstract}
Engineering Ethics is an example of a subject in which there is no single correct answer. Unlike most other courses in the engineering field, where problems have a unique answer, students need to derive an optimal solution according to the context. For the ethics course, the objective is being able to apply the ideas in practice in the real world, and this should be more of a focus than being able to understand the specialist terminology and derive model solutions. Group discussions and analysis of past cases are effective ways of cultivating this kind of ethical sense. In this study, we used an audience response system in classes and evaluated the learning benefits. Having students' own responses visualized in real time encourages active learning while still maintaining continuity of instruction. In particular, in the group presentations for ethics case studies, peer evaluations of the presentation techniques as well as the content of the ideas presented were used. Having the voting results visualized in real time was useful for encouraging students to take an active interest in listening to the presentations. This was an effective way to encourage students to come to their own conclusions while understanding the diverse range of values held by other people.
\end{abstract}

Keywords: Audience response system, Active learning, Peer evaluation, Motivation for learning, Engineering design

\section{Introduction}

The National Institutes of Technology (NIT) offer technical higher education institute in Japan. The NIT were established with the objective of cultivating practical, creative engineers, and there are now about 60,000 students studying at 57 schools (both public and private) around the country[1]. When the NIT system was first established, the idea was that these schools would train and develop "backbone engineers", but in recent years the motto has shifted to "developing a diverse range of practical and creative engineers that can be active in a wide range of more advanced areas"[2] The expectation is that these educational institutions will act as cornerstones for fostering innovation as well as for transmitting and developing technical skills in the areas of manufacturing and craftsmanship[3]. Similarly, undergraduate programs at universities also demand that students be able to effectively apply the knowledge that they acquire, through the positive adoption of active learning[4]. Against this background, universities throughout Japan are seeking to formulate frameworks for study approaches that focus on self-evaluative problem-solving, and the introduction and creation of rubric-based evaluation, such as is widely used in US higher education.

\footnotetext{
* Corresponding Author: m-shishido@tsuruoka-nct.ac.jp

$\dagger$ National Institute of Technology, Tsuruoka College 104, Sawada Inooka, Tsuruoka, Yamagata 997-8511, Japan
}

One initiative for encouraging students to take an active role in their learning is the use of an Audience Response System (ARS). These systems can collect students' answers and responses and display the results in real time. ARSs can be expected to improve students' motivation to learn because they provide a change of pace during a lesson and because students are able to give direct, honest, and anonymous feedback when they do not understand something. At the same time, teaching staff are likely to deliver better quality lessons as a result of being able to track students' understanding in real time, while improving retention, enlivening classes and also being able to save records of class data. Fig. 1 shows trends in education reforms using information and communications technology[5]. From 2009 to 2012, there was a rapid increase in e-learning and distance education using the Internet. Similarly, the utilization of ARS increased about four-fold during that period, and it seems likely to have increased even further since then. For all items surveyed, education reforms at private universities are more conspicuous than those at national or public universities. Classtalk was the first popular Classroom communication systems, begun in 1985 and commercially available from 1992 through 1999. It was developed by a former NASA engineer, with National Science Foundation funding and in collaboration with educational researchers at several major universities[6]. This system has been introduced in many American universities[7], while in Japan 


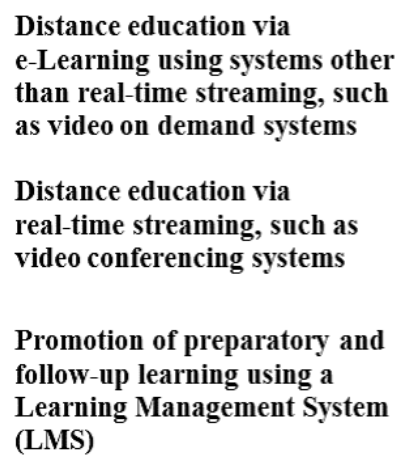

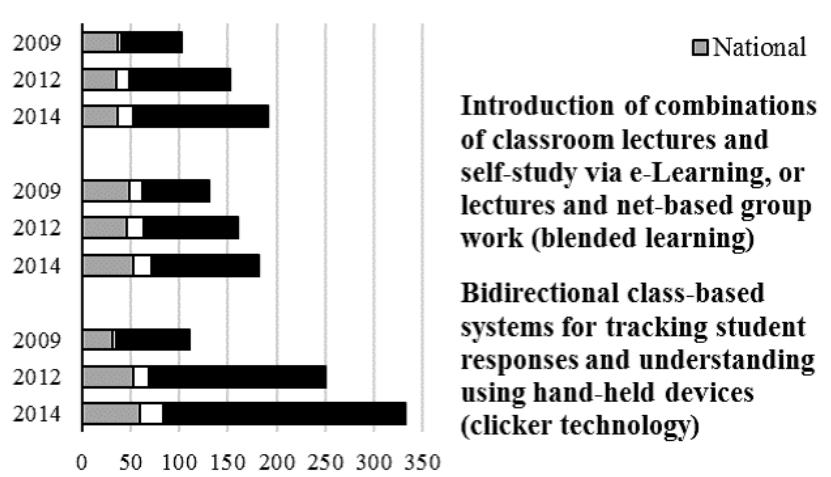

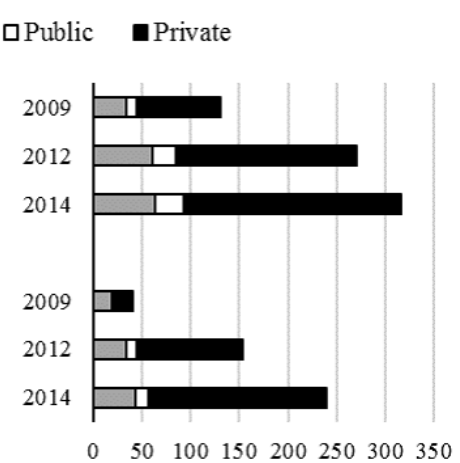

Figure 1: Trends in education reforms using information and communications technology.

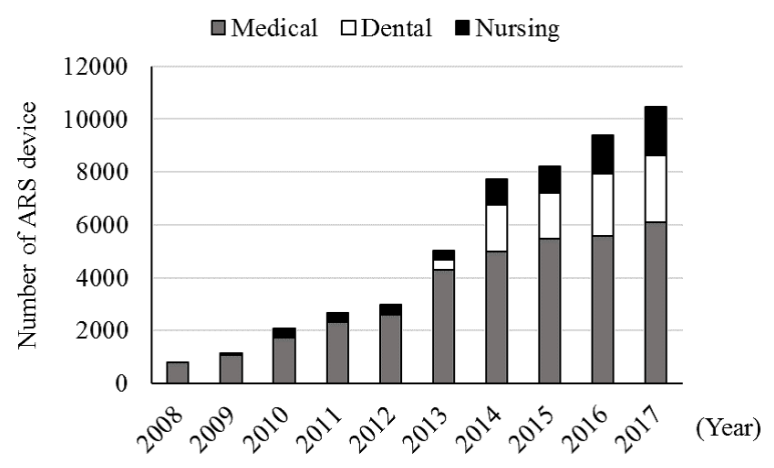

Figure 2: History of ARS adoption in Japan.

the first university to introduce Clicker, a system of this type, was Hokkaido University, where this approach has been recognized as beneficial for checking homework and preparation and for enabling students to track their own learning[8]. Other benefits reported from introducing ARSs include stimulating students' interest in lessons[9] and encouraging effective collaborative learning[10]. Fig. 2 shows a plot of the history of ARS adoptions in Japan[11]. According to a manufacturer of ARS devices, ARS have been adopted mainly in the medical, dental, and pharmacy areas, rather than in engineering. This may be because active learning is already situated as a recognized element of medical education[12].

Within the field of education in manufacturing and craftsmanship, one effective way of acquiring generic skills is engineering design (ED)education. This is because ED is situated as a subject that requires creative thinking and comprehensive learning experiences within the context of the interdisciplinary competencies that engineers are expected to master. Moreover, ED includes both generic skills (such as communication skills and the ability to apply specialist competencies to the real world) and soft skills (such as attitude and orientation to teamwork and engineering ethics)[13]. Here, the particular focus is engineering ethics. Although this subject is situated within the engineering field, where solutions are derived on the basis of rules, it is unusual in that there is often no single correct answer. As a result, students in an ethics course are required to make an overall best judgment while taking into account factors such as conflicting values, reasoning, trade-offs, and compliance. In addition to the "behavioral objective" of being able to understand technical terminology and independently derive an optimal solution, the authors of the syllabus of this subject list an "outcome objective" of being able to apply these principles to actions in the real world. In other words, the goal of the subject is not purely academic; it is, rather, the ability to apply one's own best judgment. In this sense, understanding a diverse range of perspectives and values by comparing one's own solutions to those of others is significant.

In this study, lessons were designed to apply ARS to this subject, and the outcomes were analyzed. Specifically, during presentations of the results of group work, all audience members evaluated the presentations and shared these results in real time. This initiative, intended to improve ED competency, defined here as Peer Evaluation (PE), was analyzed for efficacy.

\section{Hardware Selection and Study Method}

2.1 ARS selection There are two types of ARS: hardware-based systems, for which hand-held controllers are distributed to all participants, who use the controllers to make responses; and software-based systems, in which ARS software is installed on smartphones or tablets that are then used as remote control devices.

Table 1 shows the remote control features in ARS. For this study, a hardware-based system was adopted because there were relatively few participants and this ensured a consistent remote-control environment for all participants. The specifications and functions of the ARS devices were as follows.

Device: Clicker nano Model-H (Fine Woods. Co., Ltd.)

\section{Range: about $50 \mathrm{~m}$}

Functions used: attendance confirmation function, random lottery function, real-time comprehension function, questionnaire function

2.2 Study method Lessons were conducted using ARS continuously throughout the lecture period, followed 
Table 1: Features of ARS remote control devices

\begin{tabular}{|c|c|c|}
\hline ARS & Pros & Cons \\
\hline Hardware-based & $\begin{array}{l}\text { - All participants can share the same environment } \\
\text { (device) } \\
\text { - Operations are simple and easy to understand } \\
\text { - The devices are dedicated devices and so students } \\
\text { clearly understand that they are participating in a } \\
\text { lesson } \\
\text { - No need for a network environment }\end{array}$ & $\begin{array}{l}\text { - Significant workload for class preparation } \\
\text { (distributing and collecting devices) } \\
\text { - Remote control devices need to be main- } \\
\text { tained and managed } \\
\text { - Number of participants limited by the } \\
\text { number of devices available } \\
\text { - High cost per user } \\
\text { - Small screen display }\end{array}$ \\
\hline Software-based & $\begin{array}{l}\text { - No need to prepare, maintain, or manage remote- } \\
\text { control devices (students use their own smart de- } \\
\text { vices) } \\
\text { - Able to respond flexibly to an increased number of } \\
\text { participants (within the scope of the license agree- } \\
\text { ment) } \\
\text { - The screen display can be enlarged to the desired } \\
\text { size } \\
\text { - Questions can be displayed by sending images } \\
\text { from the teacher's computer } \\
\text { - Students can respond in text format }\end{array}$ & $\begin{array}{l}\text { - Possibility of problems displaying } \\
\text { Japanese text, depending on the environ- } \\
\text { ment } \\
\text { - Need to install a specialized app before- } \\
\text { hand } \\
\text { - Difficult for teachers to ascertain whether } \\
\text { students are using their smart devices for } \\
\text { activities unrelated to class } \\
\text { - Requires a network environment }\end{array}$ \\
\hline
\end{tabular}

by a questionnaire at the end of the term. The scope and methods for the investigation were as follows.

\section{Subject: Engineering Ethics}

Participants: 20 students in the first year of a two-year advanced program at our school

Study period: October 2016 to February 2017

Survey method:

(a) Survey items: questionnaire, observational studies, learning achievements (end of term evaluation).

(b) Survey method: participants were asked to select the most appropriate option for each of the five questions below. There was also a field for participants to enter free-form comments as necessary.

(c) Ethical considerations: prior to the survey, students were informed that the questionnaire would not be anonymous, that the content would be used for research purpose, that personal information would not be identifiable form the published statistical data, and that the content of the questionnaire would not affect their grades. Returning the questionnaire was taken as indicative of consent to cooperate with the study.

First, ARS devices were distributed to students in preparation for the lesson. Students used these devices to enter their student numbers via the ARS attendance function, and the results were reflected in a CSV file on the instructor's computer, thereby verifying the attendance situation. Practice problems were included in the slides for the lesson ahead of time, taking into account the lesson flow. At points during the lesson where student comments are required, the ARS random lottery function was trialled for choosing a student to make a comment, alongside having the teacher nominate a student to make a comment.

2.3 Deciding student groups The course in Engineering Ethics includes two group-work projects. For both of these projects, groups study and debate a topic specified

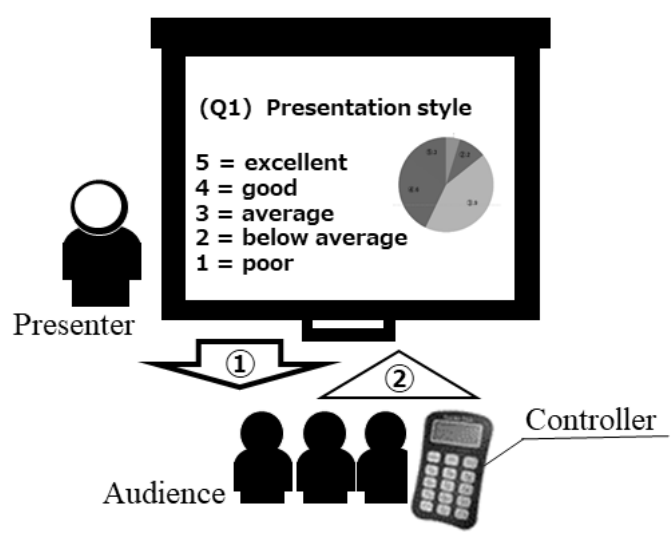

(1) Presentation (Presenter)

(2) Voting (Audience)

(3) Results are displayed on screen immediately

Figure 3: Peer evaluation for group work achievement presentation 


\begin{tabular}{|c|c|c|c|}
\hline Very good $\mathbf{5}$ & & 10 & It was interesting \\
\hline Good 4 & & 9 & I enjoyed the lesson \\
\hline Neither good nor bad 3 & 0 & & $\begin{array}{l}\text { My motivation for the class } \\
\text { has improved }\end{array}$ \\
\hline $\begin{array}{cc}\text { Not very good } & \mathbf{2} \\
\text { Not good } & \mathbf{1}\end{array}$ & $\int_{0} 1$ & $\bar{x}=4.40$ & $\begin{array}{l}\text { The system should be used } \\
\text { more often }\end{array}$ \\
\hline
\end{tabular}

\section{Boring}

ARS is not suitable for classes

ARS should not be introduced

The way the teacher operates the system was not good

Figure 4: Results of the questionnaire on applying ARS to lessons.

by the teacher, and then a representative from each group presents the results for ten minutes, followed by about ten minutes of questions and discussion. During presentations, other group members (other than the presenter) were allowed to make supplementary comments as necessary, in order to enliven the discussion.

For the first project, groups were formed by first determining a leader for each group (calling for volunteers or nominations) and then having the leaders take turns to select team members, in a manner similar to the draft system used in professional sporting leagues. For the second project, groups were determined at random. Once groups had been formed, minor adjustments were made to which students were in each group in order to even out bias in the grades between groups, taking into account the grades from the midterm assessments for the subject.

Fig. 3 shows the peer evaluation for group work achievement presentation. For both of these projects, groups study and debate a topic specified by the teacher, and then a representative from each group presents the results for ten minutes, followed by about ten minutes of questions and discussion. During presentations, other group members were allowed to make supplementary comments as necessary, in order to enliven the discussion. Peer evaluation of presentations was performed by all 19 students in the audience as well as the two teachers. Presentations were evaluated on a contest format on the basis of three parameters, had considered the topic. Each of these three parameters was scored from 1 to 5 .

\section{Results}

Fig. 4 shows the results of the questionnaire regarding the introduction of ARS to the lessons. From this, it can be seen that all students positively accepted the introduction of ARS. As for the reasons given, the majority of responses were that it was "interesting" or that they "were able to enjoy the lesson." Also, nearly half of the students indicated that introducing ARS improved their motivation to learn, and that they would like to use it more often. Students expressed positive views regarding the introduction of ARS, with no negative views recorded. Moreover, in the free-form comment field students expressed views such as "I would like to give a presentation using ARS myself", "I would like this system to be used in other classes as well", "It was meaningful that minority opinions, which might be drowned out in group discussions, could be properly reflected in the questionnaire", and "I felt that being able to see the collated results in real time gave the lesson

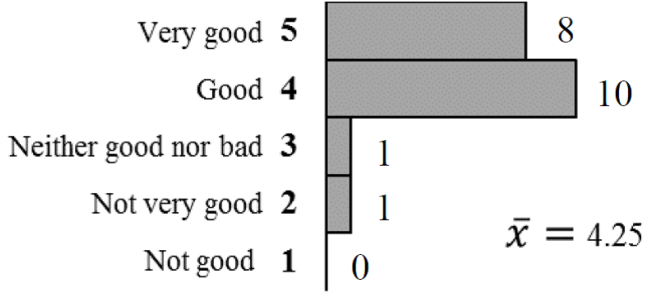

Figure 5: Question on the frequency with which ARS was used.

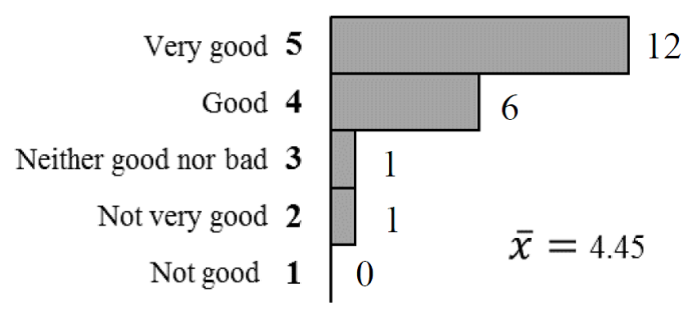

Figure 6: Question on the attendance function with ARS.

a good tempo". To provide some context for these results, it is worth noting that these students had no prior experience using ARS, and so it seems likely that their interest and attentiveness may be partially due to ARS being a new initiative.

One difficulty with ARS is the amount of work required to set up the remote-controls. Hardware remote-controls are able to provide uniform operating conditions to all participants. However, the remote-controls need to be distributed and collected at the beginning and end of each lesson, and there is also the issue of maintaining the batteries. As the number of participants increases, so too does the workload associated with preparation and maintenance. This issue can be resolved by using a software-based ARS.

Fig. 5 shows feedback on the frequency with which ARS was used during the lessons. Lessons were designed so as to prompt for responses four or five times during a 90-minute lesson, and most students indicated that this was an appropriate frequency. Note that the student who indicated that ARS was not used frequently enough also indicated in the free-form comment section that there were many instances where his opinion differed from that of the others, and he would have liked the system to have been used more often to provide more opportunities to express his views.

Fig. 6 shows feedback on the ARS attendance function. $85 \%$ of students indicated that it was very good or fairly good. In the free-form comments, there was a view that 


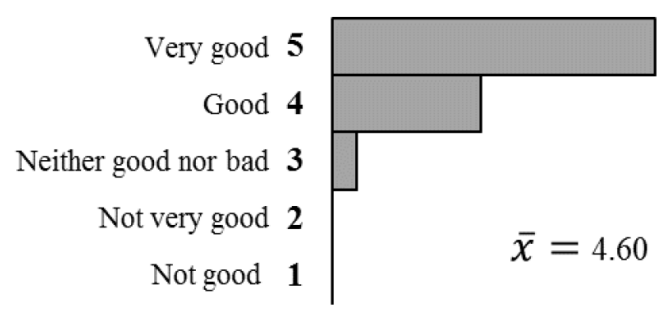

Figure 7: Question on nominating students to make comments using the ARS random lottery function.

the function was very good because it prevented inappropriate behavior by students (such as having someone else attend a class for them). Students who rated the function as "not very good" or "not good" expressed the view that there should be follow-up for latecomers.

Fig. 7 shows feedback on process of nominating students to make comments using the ARS random lottery function. $85 \%$ of students indicated that this process was "good" or "very good." Students were not allocated fixed seats during classes. From this result, the function was effective at generating a higher level of attentiveness during the lesson because students never knew when they would be called upon to make a comment as the timing was independent of where they were sitting.

Fig. 8 shows feedback on the process of peer evaluation of group presentations using ARS. $75 \%$ of students indicated this was "very good," and $95 \%$ expressed a positive view of the process, rating it as either "good" or "very good." Students were strongly supportive of the fact that the system allowed them to evaluate their own group's presenter as a member of the audience, as well as the facts that they could evaluate presentations without concern for people around them because voting was anonymous and that evaluation results were displayed to all participants in real time. The aim of this trial was to cultivate an active awareness in students that they too were participating in evaluating the presentation, not just the teacher. In keeping with this aim, for the second group presentation free-form comments included observations such as, "I was quickly disabused of the notion that I could just sit back without really paying attention", "I had a greater desire to deliver a presentation that would be well received by most of the audience", and "for highly-rated presentations the audience ratings were naturally high, and for low-rated presentations the reason for the low rating was clear". This appears to have been an excellent opportunity for students to learn about overall presentation competencies.

\section{Discussion}

The peer-evaluation results for the groupwork presentations were examined from several perspectives: the process by which group members were selected, motivation, and test grades. The relationships between these factors were also considered. Peer evaluation of presentations was performed by all 19 students in the audience (other than the presenter) as well as the two teachers. Presentations were evaluated on a contest format on the basis of three parameters: presenta-

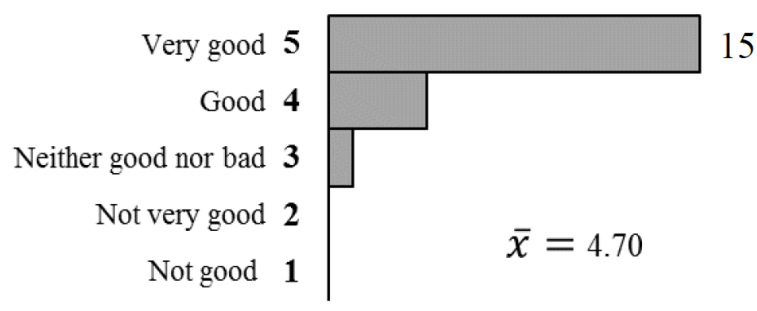

Figure 8: Question on peer evaluations on group-work presentations using ARS.

tion style, clarity of the presentation, and how thoroughly the group had considered the topic. Each of these three parameters was scored from 1 to 5 .

Fig. 9 shows the relationships between midterm grades and the results of the peer evaluations for the first round of group presentations. For Group 1 and Group 2, the group leaders volunteered for their positions, with the remaining group members selected via a draft system and chosen on the basis of who was mostly likely to be highly motivated. The radar charts indicating the evaluations of the presentations show high ratings from other students, consistent with the high levels of motivation in these two groups. Group 1 reflected on their presentation by saying "we should have examined the topic more deeply". Group 2, on the other hand, commented that "we spent adequate time discussing the topic, and overall we were satisfied with our effort". Notably, Group 2 generally scored quite highly in the midterm tests. It is clear that their motivation to take the course is connected to their learning achievements.

For the remaining groups (3, 4 and 5) the group leaders were chosen by nomination. In Group 3, the tendency was for members to be selected primarily on the basis of academic achievement. While there was a sense of incompleteness in terms of presentation techniques and depth of consideration due to the introverted personality of the presenter, the content of the presentation itself was well-received. The members of this group scored above average in the midterm tests. While the level of academic achievement was satisfactory, there was clearly room for more substantial results had they been able to improve their presentation competency.

For Group 4, members were selected on the basis of ease of communication. Although the assessment of their presentation was lower than that of Groups 1 and 2 (where the group leaders were volunteers), there is a good balance between each of the evaluation parameters. The results of the midterm tests for this group were generally good.

For Group 5, the leader was a student with a problematic attitude towards the course (frequent napping), and group members were chosen with an emphasis on friendships. While the evaluations for presentation techniques and presentation content were almost identical to those for Group 4 , this group was assessed as not having adequately considered the topic. The midterm test results for this group were generally low, and their lack of motivation was apparent in the presentation.

Fig. 10 shows the relationship between midterm grades and the results of the peer evaluations for the second round 
Midterm test grades

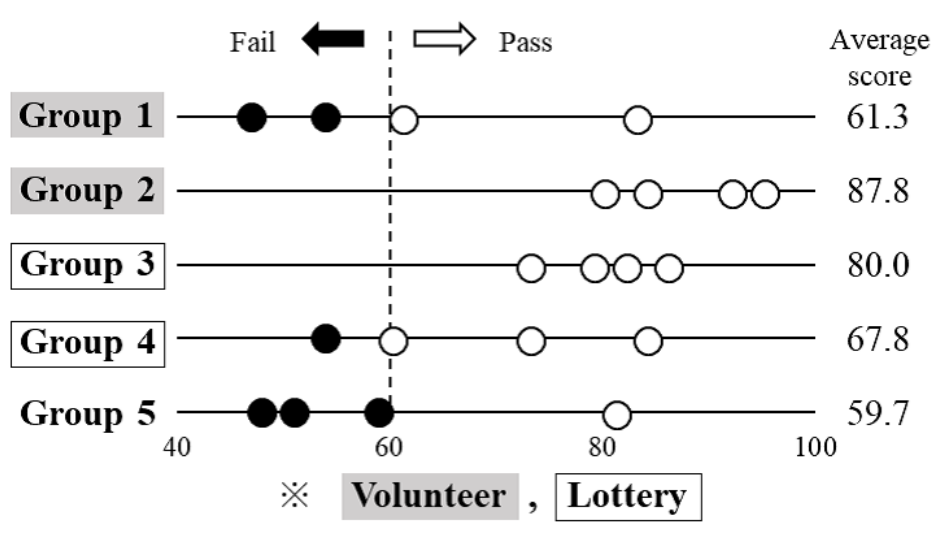

(1) Presentation style

(2) Clarity

(3) Adequate consideration
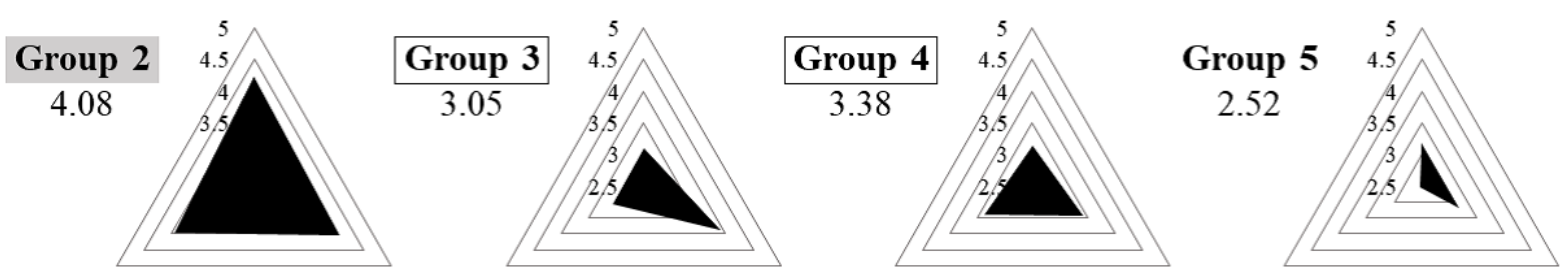

Figure 9: Relationship between midterm test grades and the peer evaluation results for the first round group presentation.

Final test grades

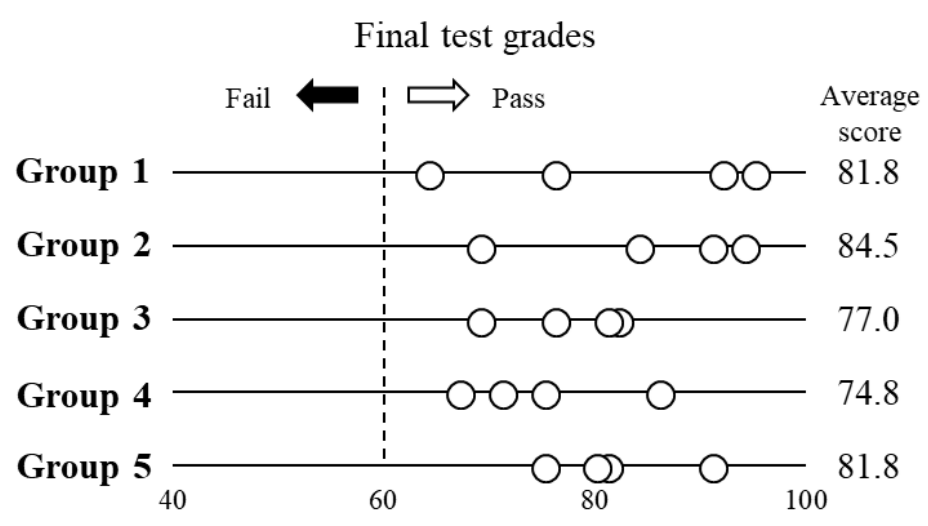

(1) Presentation style

(2) Clarity

(3) Adequate consideration
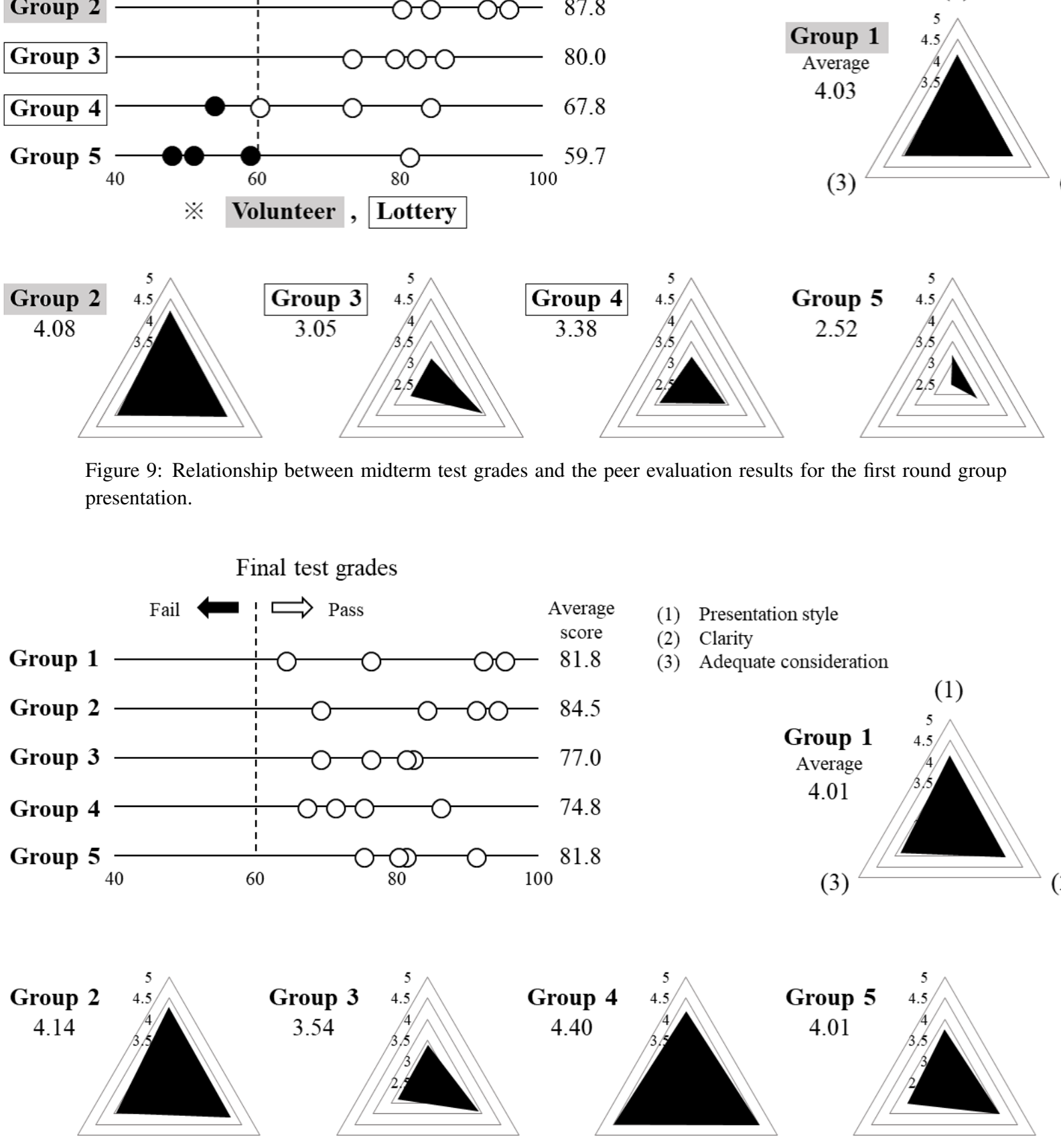

Figure 10: Relationship between end of term grades and the peer evaluation results for the second round group presentation.

of group presentations. For the second round, groups were formed at random and then adjusted so as to balance out the grades between each group, taking into account the results of the midterm tests. Variation in the presentation assessments between groups was low. Moreover, all students satisfied the learning achievements in the end of term as- sessments. These results indicate that, as a result of experiencing peer-evaluation using ARS in the first round of peer evaluations, students had an opportunity to reflect on their experiences, and this contributed to an improvement in their motivation with respect to group work. 


\section{Conclusion}

ARS was introduced to classes in Engineering Ethics, and analyzed its efficacy. Peer evaluations of work group presentations by other students were also conducted. The summary of the obtained results was shown as follows.

1) ARS utilized as a teaching support tool is highly effective at stimulating an active learning stance among students, by enabling data to be collected in real time and by visualizing the results.

2) In order to effectively utilize hardware-based ARS whereby remote controls are distributed to participants, issues requiring further consideration are the optimal enrollment numbers and how to achieve effective operations by ensuring that teaching staff master the system.

3) Peer evaluations of work group presentations, conducted in a contest format, are able to introduce a degree of competitiveness into the presentations, while also encouraging students to reflect on their performance by referring to other students' evaluations.

4) The introduction of ARS is effective as a learning support tool for developing engineering design competencies.

\section{Acknowledgement}

This work was supported by JSPS KAKENHI Grant Number JP16K04732.

\section{References}

[1] MEXT, "National Institutes of Technology (NIT)", http://www.mext.go.jp/a_menu/koutou/kousen/, [in Japanese], (accessed May 24, 2017).

[2] Central Council for Education, "Enriching Education at National Institutes of Technology" [in Japanese], December 24, 2008.

[3] Takeshi Kato, and Fumiaki Sawaura, "Possibility of Engineering Design Education in Colleges of Technology, Japan (KOSEN)", Journal of the Research Institute for Higher Education, Vol.45, pp.97-109, 2014.

[4] Central Council for Education, "Towards a Qualitative Transformation in University Education to Create a New Future-Universities that Foster Independent Thinking through Lifelong Learning", [in Japanese], August 2013.

[5] MEXT, "Status of Reforms such as Education Content at Universities (2014)", [in Japanese], http://www.mext.go.jp/a_menu/koutou/daigaku/ 04052801/1380019.htm, (accessed May 24, 2017).

[6] I. Beatty, "Transforming Student Learning with Classroom Communication Systems", EDUCAUSE Center for Applied Research Bulletin, Vol. 2004, No.3, pp.1-13, 2004.
[7] R. A. Burnstein and L. M. Lederman, "Comparison of Different Commercial Wireless Keypad Systems", The Physics Teacher, Vol.41, pp.272-275, 2003.

[8] H. Suzuki, M. Takesada, T. Hikihara, K. Yamada, T. Hosokawa and A. Onodera, "Active Learning in the Classroom using the Response System Clicker: Report of a Physics Class in Hokkaido University in 2007”, Journal of Higher Education and Lifelong Learning, Vol.16, pp.1-17, 2008.

[9] K. Yamagiwa, "Thoughts on Designing Lessons to Use Clicker Effectively", Niigata Daigaku Koutuu Kyouiku Kenkyuu (Niigata University Higher Education Research), Vol.1, No.1, pp.53-60, 2013.

[10] S. Kaneko, T. Shinmura, H. Inaba and S. Kuwamura, "Aiming for Highly Bidirectional Lessons - Exploring the Potential of Clicker", [in Japanese], Ishikawa Prefectural University Annual Report, Vol.21, pp.29-37, 2010.

[11] http://www.t-lenon.com/introduction.php (accessed May 29, 2017).

[12] Japan Accreditation Council for Medical Education (JACME), "Basic Medical Education: Japanese Specifications, Ver. 2.1", p.13, 2016.

[13] ABET, "Criteria for accrediting engineering programs", 2011-2012.

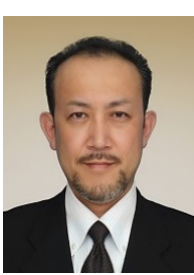

Michiaki Shishido (Member) received Ph.D. in 2008 from the Department of System and Information Engineering, Graduate School of Science and Engineering, Yamagata university. He acquired a "Professional Engineer (P.E.jp)", and is presently a professor at National Institute of Technology, Tsuruoka College. He is a member of IIAE, JSDE, MRS-J, JSMCWM, and so on.

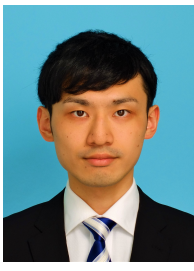

Kodai Saito (Non-member) received his associate degree from National Institute of Technology, Tsuruoka College in 2017. He has been studying at Department of Production System Engineering (Electrical and Electronic Information Course). His current research interests are Research on Efficient Group Organization in Active Learning.

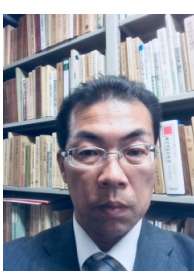

Mitsuaki Yamada(Non-member) received Ph.D. in 1996 from the Department of Japan History, Graduate School of Letters, Hokkaido University. He is presently an Associate Professor at National Institute of Technology, Tsuruoka College. His current research interests are Research on Efficient Group Organization in Active Learning.

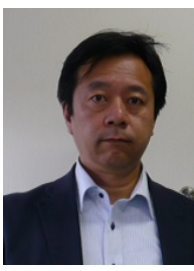

Tsukasa Sato (Non-member) received his Ph.D. degree from Nagaoka University of Technology. He is currently an associate professor at National Institute of Technology, Tsuruoka College. His current research interests are polymer engineering, material recycles and engineering design education. He is a member of SPSJ, SCEJ and JSMCWM. 
Ryoji Onodera (Non-member) received his Ph.D. degree from Niigata University in 2008. He has been working as an associate professor at National Institute of Technology, Tsuruoka College. His current research interests are development of assistive devices and systems for improving the quality of life. He is a member of JSMA, RSJ, JSWE and RESJA. 